\title{
Feasibility and early outcome of high-dose-rate Ir-192 brachytherapy as monotherapy in two fractions within 1 day for high-/very high-risk prostate cancer
}

\author{
SHINGO ASHIDA $^{1}$, ICHIRO YAMASAKI ${ }^{1}$, KENJI TAMURA ${ }^{1}$, TSUTOMU SHIMAMOTO ${ }^{1}$, \\ KEIJI INOUE $^{1}$, SHINJI KARIYA ${ }^{2}$, KANA KOBAYASHI ${ }^{2}$, TAKUJI YAMAGAMI ${ }^{2}$ and TARO SHUIN $^{1}$ \\ Departments of ${ }^{1}$ Urology and ${ }^{2}$ Diagnostic Radiology and Radiation Oncology, \\ Kochi Medical School, Nankoku, Kochi 783-8505, Japan
}

Received August 5, 2015; Accepted February 9, 2016

DOI: $10.3892 / \operatorname{mco} .2016 .786$

\begin{abstract}
The aim of the present study was to evaluate the feasibility and preliminary outcomes of high-dose-rate (HDR)-brachytherapy as a monotherapy in two fractions within 1 day for localized prostate cancer, including high-/very high-risk cases. Among the 68 patients treated with HDR monotherapy between July 2011 and December 2014, 65 had a minimal follow-up of 12 months without adjuvant androgen deprivation therapy and were enrolled in the present study [42/65 (64.6\%) exhibited high-/very high-risk diseases]. HDR monotherapy was performed in two fractions with a minimal interval of $6 \mathrm{~h}$ and the prescribed dose was $13.5 \mathrm{~Gy}$ (x2). Adverse events (AEs) were assessed using Common Terminology Criteria for Adverse Events (version 4; http://ctep.cancer.gov/protocolDevelopment/electronic_applications/ctc.htm\#ctc_40), and biochemical failure was assessed by the Phoenix definition. The median follow-up time was 30.1 months. The majority of patients had Grade 0-1 acute AEs Four patients $(6.2 \%)$ exhibited urinary retention, requiring a Foley catheter. Grade 3 acute AEs occurred at a frequency of $3.1 \%$ and hematuria at $1.5 \%$. The majority of patients also exhibited Grade 0-1 chronic AEs. Grade 3 chronic AEs occurred at a frequency of $1.5 \%$ and urethral stricture at $1.5 \%$, for which endoscopic treatment was indicated. Acute and chronic gastrointestinal AEs were uncommon, and no Grade 3 or above AEs developed. Biochemical failure occurred in 4 patients who all exhibited high-/very high-risk diseases. Kaplan-Meier estimated that 3 year biochemical failure-free survival was $91.6 \%$ overall and $88.0 \%$ in high-/very high-risk cases. The present two-fraction 1 day HDR monotherapy is
\end{abstract}

Correspondence to: Dr Shingo Ashida, Department of Urology, Kochi Medical School, Kohasu, Oko-cho, Nankoku, Kochi 783-8505, Japan

E-mail: ashidas@kochi-u.ac.jp

Key words: high-risk prostate cancer, high-dose-rate brachytherapy, monotherapy, adverse event, outcome feasible with minimal AEs and achieved acceptable biochemical control of localized prostate cancer, including high-/very high-risk cases, although long-term follow-up is required.

\section{Introduction}

Patients with prostate cancer have multiple options for radical treatment modalities for their localized disease, ranging from radical prostatectomy to radiotherapy, which includes external beam radiotherapy (EBRT), low-dose-rate (LDR)-brachytherapy (BT) and high-dose-rate (HDR)-BT. These treatments offer similar rates of biochemical control.

BT has the ability to deliver an intense radiation dose to the target, with minimal normal tissue toxicity, and achieves excellent outcomes for patients with prostate cancer $(1,2)$. LDR-BT is most frequently used for the low-risk group and HDR-BT is predominantly combined with EBRT to treat the intermediate- or high-risk groups (3-6). Certain disadvantages of HDR-BT are known when compared with LDR-BT. HDR-BT is more labor intensive and less convenient for the patients, and medical staff, due to its multi-fraction schedule. Additionally, it takes a longer period to complete the treatment, since HDR is usually performed in combination with EBRT.

In our institute, HDR-BT in combination with EBRT was initiated in July 1999. Initially, prostate cancer patients were treated with three fractions of $6 \mathrm{~Gy}$ within 2 days and subsequently EBRT (2 Gy, x20). To overcome the disadvantages of HDR-BT described above, reducing the number of fractions was attempted since November 2004, as the patients had been treated with two fractions (9 Gy, x2) within 1 day, combined with EBRT (2 Gy, x20 or 3 Gy, x13). Since July 2011, in order to make HDR-BT more convenient and more efficient, HDR-BT as a monotherapy with two fractions of 13.5 Gy delivered in 1 day was developed.

An increasing number of articles on HDR monotherapy have been reported (7). However, little is reported about high or very high-risk cases treated with 1-day HDR monotherapy. The present study reported valuable data on the feasibility and the early outcome of two-fraction 1-day HDR monotherapy for localized prostate cancer, including high-/very high-risk cases. 


\section{Materials and methods}

Patient characteristics. Between July 2011 and December 2014, 68 patients with prostate cancer were treated with HDR Ir-192 BT as a two-fraction 1-day schedule. Of these patients, 65 had a minimum follow-up of 12 months without taking adjuvant androgen deprivation therapy (ADT) and were enrolled in the present study. Patients with localized prostate cancers (T1c to T4) based on pelvic magnetic resonance imaging were included. This study was approved by institutional review board.

HDR Ir-192 BT schedule. The patients were placed in the lithotomy position under epidural anesthesia. The 7.5-MHz biplanar TRUS transducer was inserted into the rectum, and the prostate and urethra were identified. The flexible applicator needles $\left(\right.$ OncoSmart ${ }^{\circledR}$ ProGuide SharpNeedle; Elekta AB, Stockholm, Sweden) were implanted from the anterior to the posterior rows in the periphery of the prostate to minimize rotation or deformation. The remaining needles for the internal regions were subsequently implanted. All needles were inserted, penetrating $4 \mathrm{~cm}$ beyond the bladder wall to prevent needle displacement, and secured to the peritoneal region with resin and glue. Computed tomography (CT)-based planning was obtained using Oncentra ${ }^{\circledR}$ Brachy ver. 4.0 (Elekta AB). The clinical target volume (CTV) was defined by the whole prostate with a $3 \mathrm{~mm}$ margin, with the exception of the posterior region, where a $2 \mathrm{~mm}$ margin was included due to the proximity of the rectal wall. If seminal vesicle invasion was observed, the applicator needles were placed, and the seminal vesicle was included in the CTV. The planning target volume was defined as equal to the CTV. The dosimetric goals were as follows: Percentage of the prostate receiving 100 and $150 \%$ of the prescribed dose, $>90$ and $<30 \%$, respectively; minimal dose delivered to $90 \%$ of the prostate volume, $>13.5 \mathrm{~Gy}$; volume of the urethra receiving $110 \%$ of the prescribed dose, $<1 \mathrm{cc}$; and volume of the rectum receiving $75 \%$ of the prescribed dose, $<1 \mathrm{cc}$. The patients received the first fraction of the $13.5 \mathrm{~Gy}(\mathrm{x} 2)$-schedule using the microSelectron ${ }^{\circledR}$ Digital HDR-V2 (Elekta AB). The second fraction was delivered on the same day, with a minimum interval of $6 \mathrm{~h}$. CT was repeated and CT-based planning was repeatedly obtained for the second fraction to prevent inaccurate delivery due to needle displacement and/or deformation. If needle displacement into the prostate occurred, which affected an area not covered by effective dose, the needles were reinserted penetrating beyond the bladder wall and CT was repeated.

Assessment of adverse events (AEs) and statistical analysis. AEs were scored, according to the Common Terminology Criteria for Adverse Events (version 4), and the highest score encountered during each period was reported.

Biochemical failure was assessed using the Radiation Therapy Oncology Group/American Society for Therapeutic Radiology and Oncology Phoenix definition of $2 \mathrm{ng} / \mathrm{ml}$ or more above nadir prostate-specific antigen (PSA) (8). The follow-ups were 4 weeks after the treatment, every 3 months for the first 2 or 3 years for low-/intermediate- or high-/very high-risk patients, respectively, the every 6 months until 5 years, and annually thereafter. Biochemical failure-free
Table I. Patient characteristics.

\begin{tabular}{lc}
\hline Characteristic & Value \\
\hline Total patients & 65 \\
Median age, years (range) & $72(57-81)$ \\
Median initial PSA, ng/ml (range) & $13.1(4.1-57.8)$ \\
Initial PSA, $\mathrm{n}(\%)$ & \\
$<10 \mathrm{ng} / \mathrm{ml}$ & $24(36.9)$ \\
$10-20 \mathrm{ng} / \mathrm{ml}$ & $23(35.4)$ \\
$>20 \mathrm{ng} / \mathrm{ml}$ & $18(27.7)$ \\
Gleason score, $\mathrm{n}(\%)$ & \\
6 & $7(10.8)$ \\
7 & $29(44.6)$ \\
$8-10$ & $29(44.6)$ \\
Clinical T stage, $\mathrm{n}(\%)$ & \\
T1c & $17(26.2)$ \\
T2a & $14(21.5)$ \\
T2b & $9(13.8)$ \\
T2c & $3(4.6)$ \\
T3a & $18(27.7)$ \\
T3b & $3(4.6)$ \\
T4 & $1(1.5)$ \\
Risk groupa & $\mathrm{n}(\%)$ \\
Low & \\
Intermediate & $2(3.1)$ \\
High & $21(32.3)$ \\
Very high & $38(58.5)$ \\
Neoadjuvant ADT, $\mathrm{n}(\%)$ & $4(6.2)$ \\
Not administered & \\
Administered & $15(23.1)$ \\
Follow-up, months (range) & $50(76.9)$ \\
\hline & $30.1(12.0-42.7)$ \\
\hline
\end{tabular}

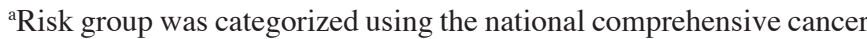
network risk group classification. PSA, prostate-specific antigen; ADT, androgen deprivation therapy.

survival (bFFS) was estimated by the Kaplan-Meier method and compared between groups using the log-rank test. All statistical analyses were performed using JMP ${ }^{\circledR}$ (SAS Institute Inc., Cary, NC, USA). $\mathrm{P}<0.05$ was considered to indicate a statistically significant difference.

\section{Results}

The characteristics of the patients are listed in Table I. The median follow-up was 30.1 months (12.0-42.7 months) and the median patient age was 72 years (57-81 years). Overall, 42/65 (64.6\%) patients exhibited high-/very high-risk prostate cancers of the National Comprehensive Cancer Network risk group classification (http://www.nccn.org/professionals/physician_gls/pdf/prostate.pdf). Neoadjuvant ADT was administered to $50(76.9 \%)$ of the patients.

The majority of patients exhibited mild acute genitourinary (GU) AEs (Table II), the most common acute GU AEs being Grade 1 frequency (47.7\%), urgency (41.5\%), urethral 
Table II. Acute adverse events occurring within 6 months of treatment.

\begin{tabular}{|c|c|c|c|c|c|c|}
\hline \multirow[b]{2}{*}{ Adverse event } & \multirow[b]{2}{*}{$\mathrm{n}$} & \multicolumn{5}{|c|}{ Grade } \\
\hline & & 0 & 1 & 2 & 3 & 4 \\
\hline \multicolumn{7}{|l|}{ Genitourinary, n (\%) } \\
\hline Frequency & 65 & $24(36.9)$ & $31(47.7)$ & $8(12.3)$ & $2(3.1)$ & $0(0)$ \\
\hline Urgency & 65 & $35(53.9)$ & $27(41.5)$ & $3(4.6)$ & $0(0)$ & $0(0)$ \\
\hline Urethral pain & 65 & $40(61.6)$ & $22(33.8)$ & $3(4.6)$ & $0(0)$ & $0(0)$ \\
\hline Retention & 65 & $51(78.4)$ & $10(15.4)$ & $4(6.2)$ & $0(0)$ & $0(0)$ \\
\hline Urinary incontinence & 65 & $38(58.5)$ & $22(33.8)$ & $5(7.7)$ & $0(0)$ & $0(0)$ \\
\hline Hematuria & 65 & $56(86.2)$ & $8(12.3)$ & $0(0)$ & $1(1.5)$ & $0(0)$ \\
\hline Urinary tract obstruction & 65 & $61(93.9)$ & $1(1.5)$ & $3(4.6)$ & $0(0)$ & $0(0)$ \\
\hline Cystitis non-infective & 65 & $65(100)$ & $0(0)$ & $0(0)$ & $0(0)$ & $0(0)$ \\
\hline \multicolumn{7}{|l|}{ Gastrointestinal, n (\%) } \\
\hline Diarrhea & 65 & $64(98.5)$ & $1(1.5)$ & $0(0)$ & $0(0)$ & $0(0)$ \\
\hline Rectal hemorrhage & 65 & $63(96.9)$ & $2(3.1)$ & $0(0)$ & $0(0)$ & $0(0)$ \\
\hline Proctitis & 65 & $64(98.5)$ & $1(1.5)$ & $0(0)$ & $0(0)$ & $0(0)$ \\
\hline Rectal pain & 65 & $65(100)$ & $0(0)$ & $0(0)$ & $0(0)$ & $0(0)$ \\
\hline Fecal incontinence & 65 & 63 (96.9) & $2(3.1)$ & $0(0)$ & $0(0)$ & $0(0)$ \\
\hline Rectal fistula & 65 & $65(100)$ & $0(0)$ & $0(0)$ & $0(0)$ & $0(0)$ \\
\hline
\end{tabular}

Table III. Chronic adverse events that developed after 6 months of treatment.

\begin{tabular}{|c|c|c|c|c|c|c|}
\hline \multirow[b]{2}{*}{ Adverse event } & \multirow[b]{2}{*}{$\mathrm{n}$} & \multicolumn{5}{|c|}{ Grade } \\
\hline & & 0 & 1 & 2 & 3 & 4 \\
\hline Genitourinary, n (\%) & & & & & & $0(0)$ \\
\hline Frequency & 65 & $37(57.0)$ & $26(40.0)$ & $1(1.5)$ & $1(1.5)$ & $0(0)$ \\
\hline Urgency & 65 & $38(58.5)$ & $26(40.0)$ & $1(1.5)$ & $0(0)$ & $0(0)$ \\
\hline Urethral pain & 65 & $50(76.9)$ & $14(21.6)$ & $1(1.5)$ & $0(0)$ & $0(0)$ \\
\hline Retention & 65 & $57(87.7)$ & $6(9.2)$ & $2(3.1)$ & $0(0)$ & $0(0)$ \\
\hline Urinary incontinence & 65 & $45(69.2)$ & $14(21.6)$ & $6(9.2)$ & $0(0)$ & $0(0)$ \\
\hline Hematuria & 65 & $62(95.4)$ & $2(3.1)$ & $1(1.5)$ & $0(0)$ & $0(0)$ \\
\hline Urinary tract obstruction & 65 & $60(92.3)$ & $0(0)$ & $4(6.2)$ & $1(1.5)$ & $0(0)$ \\
\hline Cystitis non-infective & 65 & $65(100)$ & $0(0)$ & $0(0)$ & $0(0)$ & $0(0)$ \\
\hline \multicolumn{7}{|l|}{ Gastrointestinal, n (\%) } \\
\hline Diarrhea & 65 & $65(100)$ & $0(0)$ & $0(0)$ & $0(0)$ & $0(0)$ \\
\hline Rectal hemorrhage & 65 & $63(96.9)$ & $2(3.1)$ & $0(0)$ & $0(0)$ & $0(0)$ \\
\hline Proctitis & 65 & $63(96.9)$ & $2(3.1)$ & $0(0)$ & $0(0)$ & $0(0)$ \\
\hline Rectal pain & 65 & $65(100)$ & $0(0)$ & $0(0)$ & $0(0)$ & $0(0)$ \\
\hline Fecal incontinence & 65 & $62(95.4)$ & $2(3.1)$ & $1(1.5)$ & $0(0)$ & $0(0)$ \\
\hline Rectal fistula & 65 & $65(100)$ & $0(0)$ & $0(0)$ & $0(0)$ & $0(0)$ \\
\hline
\end{tabular}

pain $(33.8 \%)$ and urinary incontinence $(33.8 \%)$. The rate of Grade 2 acute GU AEs was $<10 \%$, with the exception of frequency $(12.3 \%)$. A total of four patients $(6.2 \%)$ had urinary retention, requiring a temporary Foley catheter, and 3 patients developed Grade 3 AEs: Of those, 2 (3.1\%) with frequency and one $(1.5 \%)$ with hematuria. No other Grade 3 acute GU AEs were reported. As for acute gastrointestinal (GI) AEs, only 5 patients experienced mild diarrhea, rectal hemorrhage, proctitis or fecal incontinence, and no Grade 2 or 3 acute GI AEs occurred.

With regards to chronic AEs, 1 patient (1.5\%) exhibited the Grade $3 \mathrm{GU}$ AE of frequency (Table III). This patient developed Grade 3 urinary stricture 9 months after HDR-BT and required endoscopic treatment. Other than Grade 2 GU urinary incontinence $(9.2 \%)$ and urinary tract obstruction $(6.2 \%)$, the rate of Grade 2 GU AEs was $<5 \%$. No Grade 2 or 3 chronic GI 
Table IV. Characteristics of four patients with biochemical failure.

\begin{tabular}{lcccccc}
\hline Age (years) & $\begin{array}{c}\text { Initial PSA } \\
(\mathrm{ng} / \mathrm{ml})\end{array}$ & $\begin{array}{c}\text { Gleason } \\
\text { score }\end{array}$ & $\begin{array}{c}\text { Clinical T } \\
\text { stage }\end{array}$ & $\begin{array}{c}\text { Risk } \\
\text { group }^{\mathrm{a}}\end{array}$ & $\begin{array}{c}\text { Neoadjuvant } \\
\text { ADT }\end{array}$ & $\begin{array}{c}\text { Time to biochemical } \\
\text { failure (months) }\end{array}$ \\
\hline 62 & 33.6 & $4+4$ & $2 \mathrm{~b}$ & High & Administered & 30.1 \\
72 & 12.5 & $4+4$ & $2 \mathrm{~b}$ & High & Administered & 22.2 \\
67 & 54.9 & $4+3$ & $3 \mathrm{~b}$ & Very high & Administered & 14.8 \\
75 & 17.2 & $5+4$ & $2 \mathrm{a}$ & High & Administered & 18.3 \\
\hline
\end{tabular}

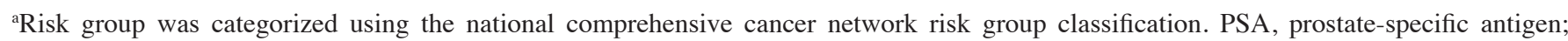
ADT, androgen deprivation therapy.

AEs developed, with the exception of one patient with chronic Grade 2 fecal incontinence.

A total of 4 patients $(6.2 \%)$ had PSA failure, 3 had high-risk cancers, and 1 patient had very high-risk cancer that recurred 14.8 months after the treatment (Table IV). Fig. 1 demonstrates the estimates of freedom from biochemical failure for HDR-BT as monotherapy. The rates of 3-year bFFS were $91.6 \%$ overall (Fig. 1A) and $88.0 \%$ in high-/very high-risk patients (Fig. 1B). Excluding the 2 patients with low-risk disease, no significant difference in bFFS between the intermediate- and high-/very high-risk groups existed (P=0.21; Fig. 1B).

\section{Discussion}

HDR-BT was first introduced at Kiel University, Germany in 1986 (9). HDR-BT was initially performed as a boost in combination with EBRT. In 1995, the first trial of HDR-BT as a monotherapy was introduced at Osaka University, Japan (10). Since then, $>80$ articles and abstracts on HDR monotherapy have been published, with a variety of doses and fractionations (7).

From the perspective of the radiobiology of HDR-BT schedules and biologic equivalent dose (BED), the radiation schedule of $13.5 \mathrm{~Gy}$ (x2) was used in the present study. Notably, when applying the standard linear quadratic model $[\mathrm{BED}=$ number of fractions $\mathrm{x}$ dose per fraction $(1+\mathrm{d} / \alpha / \beta)]$, with an $\alpha / \beta$ ratio of 1.5 , the BED of the $13.5 \mathrm{~Gy}$ (x2) schedule was $261 \mathrm{~Gy}$, which is markedly higher compared with the BED of the EBRT schedule of $1.8 \mathrm{~Gy}(\mathrm{x} 45$; BED = $178 \mathrm{~Gy})(11)$.

In the present study, the data indicated the low toxicity of HDR-BT as monotherapy in two fractions within one day. The AE data presented are similar to the data from a previously published HDR monotherapy series (11), which favorably compared with those from an LDR-BT series (12-15). Zelefsky et al (16) reported that the 5 year likelihood of urethral stricture development was $10 \%$, and the median duration until stricture development was 18 months. The median follow-up of the present series was 30.1 months. Therefore, it is unlikely that the rate of urethral strictures will significantly change with longer follow-up (Tables II and III). Zamboglou et al (17) recently reported a large series in which 718 patients were treated with HDR monotherapy. This previous study showed that late Grade $3 \mathrm{GU}$ toxicity was $3.5 \%$, which compared favorably with $3.1 \%$ in the present series. Yoshioka et al $(18,19)$ reported that the rate of Grade 2-3 chronic rectal bleeding was $\sim 10 \%$ after HDR monotherapy was delivered with a total dose
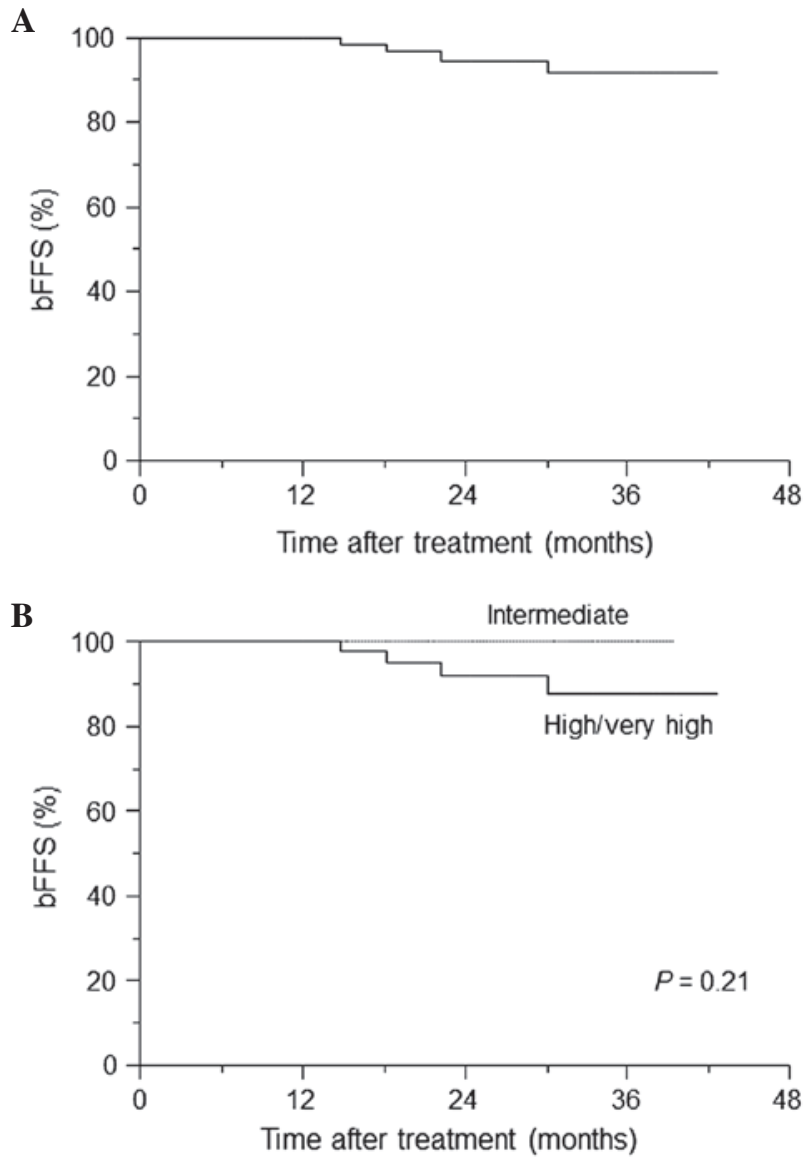

Figure 1. Kaplan-Meier curve of bFFS. The bFFS was calculated for (A) all patients and for (B) intermediate- and high-/very high-risk patients. The log-rank P-value is indicated. bFFS, biochemical failure-free survival.

of $54 \mathrm{~Gy}$ in nine fractions within 5 days. The GI toxicity of the present two-fraction schedule was minimal, and no Grade 2 or greater GI AEs developed, with the exception of one patient with chronic Grade 2 fecal incontinence. The present study hypothesized that the reproducibility of dosimetry is most important to prevent AEs, and repeated CT planning prior to the second treatment is necessary.

The majority of patients received neoadjuvant ADT for 3-6 months. Certain patients with a median follow up of 30.1 months may still be under the influence of ADT, as well as HDR-BT. Therefore, the present biochemical outcome data remains relatively early. However, the data are important 
as an early indicator of the efficacy of this technique. The American Brachytherapy Society (ABS) guidelines for HDR prostate BT support the use of HDR monotherapy for localized prostate cancer and quote biochemical control rates of 85-100, 81-100 and 43-93\% for low-, intermediate- and high-risk prostate cancers, respectively (20). Yoshioka et al (21) recently reported that the three-year PSA failure-free rates of intermediate- and high-risk patients were 96 and $90 \%$, respectively, for the $45.5 \mathrm{~Gy} / 7$ fractions regimen, and 93 and $85 \%$, respectively, for the $54 \mathrm{~Gy} / 9$ fractions regimen. Zamboglou et al (17) showed that the 3,5 and 8 year biochemical control rates were 97, 94 and $90 \%$, with no significant differences between the risk groups. In our cohort, $91.6 \%$ of patients overall were free of biochemical relapse at 3 years. Of those, 100 and $88.0 \%$ exhibited intermediateand high-/very high-risk diseases. The technique reported in the present study achieves excellent bFFS rates, similar to the published data and at the upper end of data quoted by the ABS guidelines. Finally, HDR monotherapy is not associated with any significant increase in AEs or reductions in efficacy when compared with our conventional HDR-BT with EBRT, which achieved bFFSs of 91.7 and $82.5 \%$ for 3 and 5 years, respectively, in the high-risk group (data not shown).

\section{References}

1. Crook J: The role of brachytherapy in the definitive management of prostate cancer. Cancer Radiother 15: 230-237, 2011.

2. Ghilezan M: Role of high dose rate brachytherapy in the treatment of prostate cancer. Cancer Radiother 16: 418-422, 2012.

3. Hoskin PJ, Colombo A, Henry A, Niehoff P, Paulsen Hellebust T, Siebert FA and Kovacs G: GEC/ESTRO recommendations on high dose rate afterloading brachytherapy for localised prostate cancer: An update. Radiother Oncol 107: 325-332, 2013.

4. Hoskin PJ, Rojas AM, Bownes PJ, Lowe GJ, Ostler PJ and Bryant L: Randomised trial of external beam radiotherapy alone or combined with high-dose-rate brachytherapy boost for localised prostate cancer. Radiother Oncol 103: 217-222, 2012.

5. Langley S, Laing R, Henderson A, Aaltomaa S, Kataja V, Palmgren JE, Bladou F, Salem N, Serment G, Nava L, et al: European collaborative group on prostate brachytherapy: Preliminary report in 1175 patients. Eur Urol 46: 565-570; discussion 570, 2004.

6. Zwahlen DR, Andrianopoulos N, Matheson B, Duchesne GM and Millar JL: High-dose-rate brachytherapy in combination with conformal external beam radiotherapy in the treatment of prostate cancer. Brachytherapy 9: 27-35, 2010.

7. Demanes DJ and Ghilezan MI: High-dose-rate brachytherapy as monotherapy for prostate cancer. Brachytherapy 13: 529-541, 2014.

8. Roach MIII,Hanks G, Thames H Jr, SchellhammerP, Shipley WU, Sokol GH and Sandler H: Defining biochemical failure following radiotherapy with or without hormonal therapy in men with clinically localized prostate cancer: Recommendations of the RTOG-ASTRO Phoenix Consensus Conference. Int J Radiat Oncol Biol Phys 65: 965-974, 2006.
9. Kovács G, Galalae R, Loch T, Bertermann H, Kohr P, Schneider R and Kimming B: Prostate preservation by combined external beam and HDR brachytherapy in nodal negative prostate cancer. Strahlenther Onkol 175 (Suppl 2): S87-S88, 1999.

10. Yoshioka Y, Nose T, Yoshida K, Inoue T, Yamazaki H, Tanaka E, Shiomi H, Imai A, Nakamura S, Shimamoto S and Inoue T: High-dose-rate interstitial brachytherapy as a monotherapy for localized prostate cancer: Treatment description and preliminary results of a phase I/II clinical trial. Int J Radiat Oncol Biol Phys 48: 675-681, 2000.

11. Ghilezan M, Martinez A, Gustason G, Krauss D, Antonucci JV, Chen P, Fontanesi J, Wallace M, Ye H, Casey A, et al: High-dose-rate brachytherapy as monotherapy delivered in two fractions within one day for favorable/intermediate-risk prostate cancer: Preliminary toxicity data. Int J Radiat Oncol Biol Phys 83: 927-932, 2012.

12. Anderson JF, Swanson DA, Levy LB, Kuban DA, Lee AK, Kudchadker R, Phan J, Bruno T and Frank SJ: Urinary side effects and complications after permanent prostate brachytherapy: The MD Anderson cancer center experience. Urology 74: 601-605, 2009.

13. Crook J, Fleshner N, Roberts C and Pond G: Long-term urinary sequelae following 125 iodine prostate brachytherapy. J Urol 179: 141-145; discussion 146, 2008.

14. Keyes M, Miller S, Moravan V, Pickles T, McKenzie M, Pai H, Liu M, Kwan W, Agranovich A, Spadinger I, et al: Predictive factors for acute and late urinary toxicity after permanent prostate brachytherapy: Long-term outcome in 712 consecutive patients. Int J Radiat Oncol Biol Phys 73: 1023-1032, 2009.

15. Merrick GS, Butler WM, Wallner KE, Galbreath RW, Allen ZA, Gutman S and Lief J: Long-term rectal function after permanent prostate brachytherapy. Cancer J 13: 95-104, 2007.

16. Zelefsky MJ, Hollister T, Raben A, Matthews S and Wallner KE: Five-year biochemical outcome and toxicity with transperineal CT-planned permanent I-125 prostate implantation for patients with localized prostate cancer. Int J Radiat Oncol Biol Phys 47: 1261-1266, 2000.

17. Zamboglou N, Tselis N, Baltas D, Buhleier T, Martin T, Milickovic N, Papaioannou S, Ackermann H and Tunn UW: High-dose-rate interstitial brachytherapy as monotherapy for clinically localized prostate cancer: Treatment evolution and mature results. Int J Radiat Oncol Biol Phys 85: 672-678, 2013.

18. Yoshioka Y, Konishi K, Sumida I, Takahashi Y, Isohashi F, Ogata T, Koizumi M, Yamazaki H, Nonomura N, Okuyama A and Inoue T: Monotherapeutic high-dose-rate brachytherapy for prostate cancer: Five-year results of an extreme hypofractionation regimen with 54 Gy in nine fractions. Int J Radiat Oncol Biol Phys 80: 469-475, 2011.

19. Yoshioka Y, Nose T, Yoshida K, Oh RJ, Yamada Y, Tanaka E, Yamazaki H, Inoue T and Inoue T: High-dose-rate brachytherapy as monotherapy for localized prostate cancer: A retrospective analysis with special focus on tolerance and chronic toxicity. Int J Radiat Oncol Biol Phys 56: 213-220, 2003.

20. Yamada Y, Rogers L, Demanes DJ, Morton G, Prestidge BR Pouliot J, Cohen GN, Zaider M, Ghilezan M and Hsu IC; American Brachytherapy Society: American brachytherapy society consensus guidelines for high-dose-rate prostate brachytherapy. Brachytherapy 11: 20-32, 2012.

21. Yoshioka Y, Konishi K, Suzuki O, Nakai Y, Isohashi F, Seo Y, Otani Y, Koizumi M, Yoshida K, Yamazaki H, et al: Monotherapeutic high-dose-rate brachytherapy for prostate cancer: A dose reduction trial. Radiother Oncol 110: 114-119, 2014. 